\title{
Práticas de conversão do conhecimento no centro de investigação e prevenção de acidentes aeronáuticos
}

\section{Knowledge conversion practices at the aeronautical accident investigation and prevention center}

\author{
Adriano Barbosa Maia Especialista em Gestão e Planejamento Estratégicos. Centro Universitário do Sul de Minas \\ (UNISMG) - Brasil. Bacharel em Ciências Aeronáuticas pela Academia da Força Aérea - AFA. \\ Brasil. adrianomaia.fab@gmail.com \\ Rodrigo Franklin Frogeri Doutorando em Sistemas de Informação e Gestão do Conhecimento - Universidade FUMEC - \\ Brasil. Professor no Centro Universitário do Sul de Minas - UNISMG. \\ rodrigo.frogeri@professor.unis.edu.br \\ Pedro dos Santos Portugal Júnior Pós-doutor em Desenvolvimento Econômico. Universidade de Campinas - Brasil. Professor no \\ Centro Universitário do Sul de Minas - UNISMG. pedro.junior@professor.unis.edu.br
}

\section{RESUMO}

Este estudo analisa a aplicação de princípios de Gestão do Conhecimento no Laboratório de Leitura e Análise de Dados de Gravadores de Voo (LABDATA), setor pertencente ao Centro de Investigação e Prevenção de Acidentes Aeronáuticos. Tal abordagem se justifica pelo alto valor agregado ao conhecimento do corpo técnico do LABDATA, único setor na América Latina responsável pela atividade de extração, obtenção e análise de dados de gravadores de voo. $O$ estudo teve como objetivo compreender e analisar a aplicação de princípios de Gestão do Conhecimento no LABDATA. Este intento foi alcançado mediante uma abordagem qualitativa, realizada por meio de um estudo de caso e entrevistas semiestruturadas analisadas à luz da técnica de análise de conteúdo. O estudo está aprovado no Comitê de Ética em Pesquisa sob o registro 96852518.7.0000.5111. A pesquisa evidenciou que os modos de conversão de conhecimento de socialização e externalização favorecem a criação e compartilhamento de conhecimento no LABDATA. Contudo, foram observadas debilidades nos modos de conversão de combinação e de internalização. Traços culturais brasileiros emergiram no estudo como fatores que podem influenciar nos modos de conversão do conhecimento.

Palavras-chave: Espiral do Conhecimento. Força Aérea Brasileira. Centro de Investigação e Prevenção de Acidentes Aeronáuticos. Conhecimento tácito. Conhecimento explícito.

\begin{abstract}
Knowledge Management (KM) seeks to systematize processes to support the identification, generation, sharing and application of organizational knowledge in order to maximize efficiency and return on an organization's knowledge assets. The Laboratory of Reading and Analysis of Flight Recorders Data (LABDATA), a sector belonging to the Center for Research and Prevention of Aeronautical Accidents, retains all the knowledge of a Brazilian aeronautical sector that provides services to different countries, requiring practices that allow the externalization of tacit and explicit knowledge of its members. This study aims to understand and analyse knowledge conversion practices within LABDATA. It is justified by the high added value to the knowledge of LABDATA's technical staff, the only sector in Latin America responsible for the extraction, acquisition and analysis of flight recorder data. The objective of the study was achieved through a qualitative approach, carried out through a case study and semi-structured interviews analyzed in light of the content analysis technique. The research showed that the modes of knowledge conversion of socialization and externalization favor the creation and sharing of knowledge in LABDATA. However, weaknesses were observed in the modes of combination conversion and internalization. Brazilian cultural traits emerged in the study as factors that can influence the modes of knowledge conversion.
\end{abstract}

Keywords: Knowledge Spiral. Brazilian Air Force. Innovation. Tacit Knowledge. Explicit knowledge. 


\section{INTRODUÇÃO}

O Centro de Investigação e Prevenção de Acidentes Aeronáuticos (CENIPA) é uma organização do Comando da Aeronáutica Brasileira responsável por planejar, gerenciar, controlar e executar as atividades relacionadas com a prevenção e investigação de acidentes aeronáuticos. O Laboratório de Leitura e Análise de Dados de Gravadores de Voo (LABDATA), setor pertencente ao CENIPA, tem por atribuição efetuar a extração, obtenção e análise de dados de gravadores de voo envolvidos em ocorrências aeronáuticas. Destaca-se que o setor é o único voltado para a atividade de extração (obtenção de dados em gravadores danificados), obtenção e análise de dados de gravadores de voo na América Latina. Nesse sentido, observa-se que tal expertise está presente em poucas autoridades governamentais de investigação aérea, das quais destacam-se os Estados Unidos, Canadá, Austrália, Rússia, França, Alemanha, Itália, Reino Unido, Irlanda, Taiwan, Malásia, Japão e Arábia Saudita.

A atividade de investigação de acidentes aeronáuticos, segundo o Anexo 13 da Convenção de Aviação Civil Internacional (BRASIL, 2017) é, em princípio, de responsabilidade da autoridade governamental do Estado da localidade de ocorrência do evento. Paralelamente, os estados de registro, do operador, do projeto, bem como de fabricação de aeronaves poderão nomear representantes acreditados nas investigações de países estrangeiros. Tal fato, remete a uma grande visibilidade e representatividade do Estado Brasileiro em virtude da existência da companhia brasileira Embraer S.A. Destarte, o LABDATA, amplia suas atividades em parceria com outros países, em especial aqueles que não possuem estrutura específica para manipular gravadores de voo e que possuem aeronaves fabricadas pela Embraer, destacando-se países da América Latina e África. $\mathrm{O}$ universo de recursos humanos da Força Aérea Brasileira (FAB) que lida com a atividade de manipular gravadores de voo é bastante restrito em termos quantitativos, sendo apenas três militares. O pequeno efetivo retém todo o conhecimento de um setor da aeronáutica brasileira que presta serviços a diferentes países, exigindo práticas que permitam a externalização dos conhecimentos tácitos e explícitos dos seus integrantes.

Segundo Wilson (2001, p. 312), a Gestão do Conhecimento (GC) é definida como "processos sistemáticos, articulados e intencionais, apoiados na identificação, geração, compartilhamento e aplicação do conhecimento organizacional com objetivo de maximizar a eficiência e o retorno sobre os ativos de conhecimento da organização". Discute-se que a criação e utilização do conhecimento ocorre por meio de quatro relações bilaterais entre o conhecimento tácito e explícito (NONAKA; TAKEUCHI, 2008). Os modos de conversão do conhecimento podem ocorrer continuamente, por meio de um ciclo denominado SECl (Socialização, Externalização, Combinação e Internalização). Mohsen Allameh et al. (2014) argumentam que o compartilhamento do conhecimento tácito e explícito em uma organização pode influenciar positivamente no seu desempenho por meio da melhoria dos processos de negócios e da prestação de serviços. Para Maravilhas e Martins (2019) se, por um lado, uma organização não pode funcionar sem informação e conhecimento, por outro, é importante saber como utilizar este recurso para melhorar a sua utilização.

Destarte, o estudo objetivou compreender e analisar as práticas de conversão do conhecimento no âmbito do LABDATA. Este intento foi conseguido por meio de um estudo de caso com abordagem qualitativa e levantamento de dados com entrevistas semiestruturadas, analisadas por meio da técnica de análise de conteúdo (BARDIN, 2016). Para nortear o estudo, definiu-se a seguinte pergunta de pesquisa: o comportamento do efetivo do LABDATA aplica práticas para a criação, aquisição, integração e compartilhamento do conhecimento de acordo com o que preconiza a literatura de Gestão do Conhecimento? $O$ estudo justifica-se no plano organizacional pelo fato do efetivo do LABDATA possuir um quantitativo bastante reduzido, interdisciplinar e com considerável conhecimento tácito, urgindo por práticas de GC que venham a permitir a devida explicitação e disseminação das rotinas profissionais. No plano acadêmico, o trabalho contribui com uma abordagem na administração pública brasileira pouco observada (SILVA; MIRANDA, 2018) e sob um campo que demanda constante evolução. 


\section{DESENVOLVIMENTO}

A base teórica do estudo foi estruturada em quatro temas centrais. Inicialmente, os temas conhecimento tácito e explícito são conceituados . Na sequência, o processo SECI (Socialização, Externalização, Combinação e Internalização) é apresentado. A temática gestão do conhecimento compila os temas anteriores em um contexto organizacional. Por fim, estudos correlatos à aplicação de práticas de conversão do conhecimento são discutidos.

\subsection{Conhecimento tácito e explícito}

Segundo Nonaka e Takeuchi (2008, p. 19), os conhecimentos tácito e explícito são alinhados à uma contextualização da atual sociedade do conhecimento, em que se observa a importância da aceitação e o cultivo de contrastes de conhecimentos, os quais paradoxalmente apontam para "as inconsistências, os dilemas, as dualidades, as polaridades, as dicotomias e as oposições". Nesse sentido, o termo é formado por dois elementos aparentemente opostos, tais quais o conhecimento tácito e o conhecimento explícito.

O conhecimento tácito aborda um conhecimento pessoal, que se relaciona ao contexto, vincula-se às características individuais das pessoas, como valores, emoções, propósitos. Remetem à maior dificuldade de mapeamento por serem subjetivos. O conhecimento tácito se relaciona ao processo de interação, comunicação e coordenação de conhecimento ou de experiência (HASS; HANSEN, 2007). Nonaka e Takeuchi (2008) consideram que o conhecimento tácito não é facilmente visível e explicado, possuindo características de pessoalidade, difícil formalização, compartilhamento, intuição, palpites subjetivos, bem como ideias, valores ou emoções ligadas aos indivíduos.

Ainda segundo Nonaka e Takeuchi (2008, p.19), o conhecimento explícito, por sua vez, "pode ser expresso em palavras, números ou sons, e compartilhado na forma de dados, fórmulas científicas, recursos visuais, fitas de áudio, especificações de produtos ou manuais." Este conhecimento está presente quando o indivíduo explicita o seu conhecimento em uma forma "concreta", passível de ser adquirido por outro sem a intervenção do seu criador. Para explicar a conversão do conhecimento tácito para explícito, Nonaka e Takeuchi (2008) estabeleceram um processo, sendo discutido a seguir.

\subsection{Modos de conversão do conhecimento}

Nonaka e Takeuchi (2008) teorizaram que a criação e utilização do conhecimento em uma organização deve envolver a relação entre o conhecimento tácito e explícito. Os autores preconizam relações de conversão bilaterais, podendo ser observados quatro modos, a saber: (i) Socialização: De tácito para tácito; (ii) Externalização: De tácito para explícito; (iii) Combinação: De explícito para explícito; e (iv) Internalização: De explícito para tácito.

Considera-se que tais modos de conversão do conhecimento podem ocorrer continuamente, por meio de um ciclo SECI (Socialização, Externalização, Combinação e Internalização). O ciclo é ilustrado por uma espiral (Figura 1). Na medida em que as etapas do ciclo são realizadas o conhecimento tácito é explicitado e um novo aprendizado é estabelecido. O ciclo SECI se mantém em um processo evolutivo do conhecimento. 
Figura 1 - Processo SECI

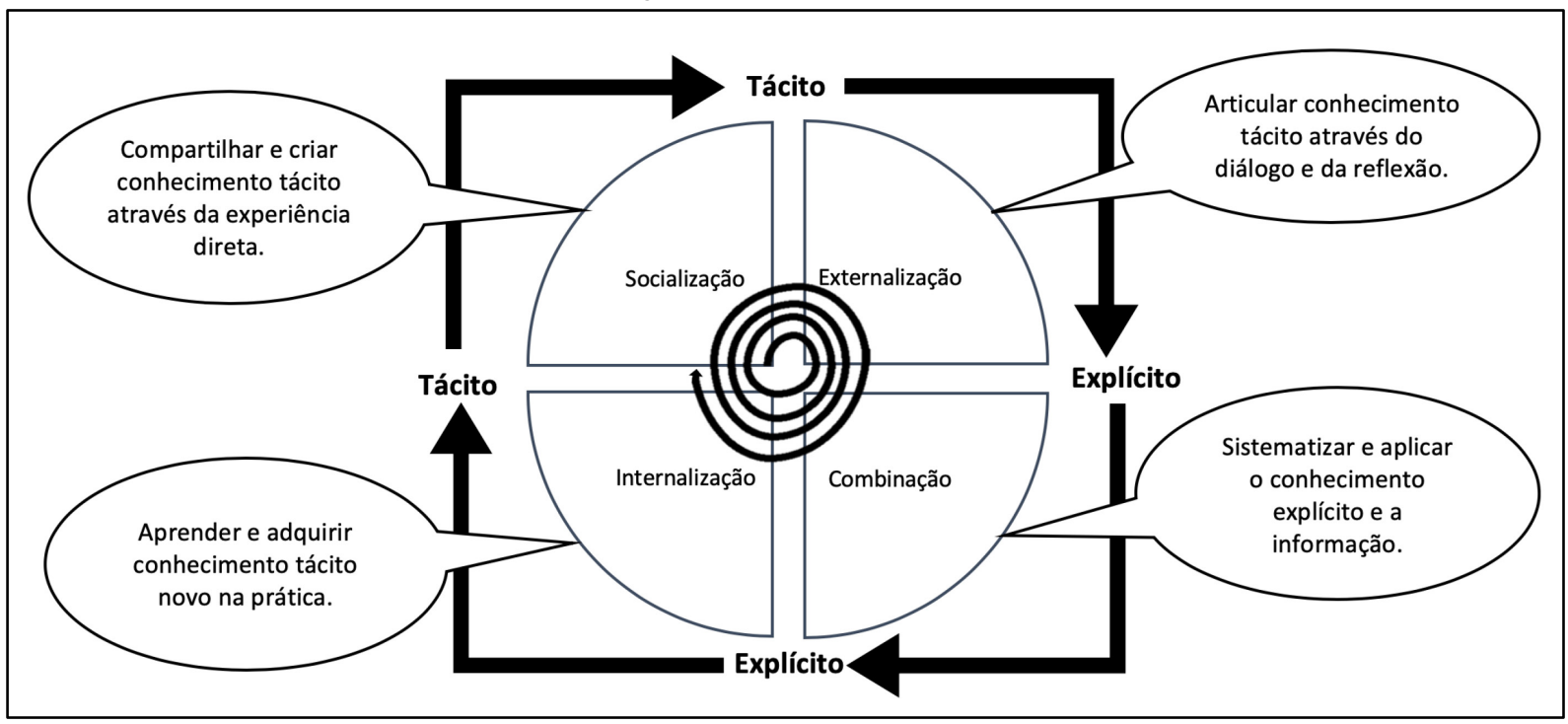

Fonte: Nonaka e Takeuchi (2008, p. 24).

Nonaka e Takeuchi (2008, p. 23) definem o incremento do conhecimento diante das formas de conversão. Na socialização, o conhecimento tácito é compartilhado e/ou criado por meio de experiências diretas. Na etapa de externalização, o conhecimento tácito é articulado com diálogos e reflexões. Na sequência, a etapa de combinação busca sistematizar e aplicar o conhecimento explícito e a informação. Por fim, na internalização, há o aprendizado e aquisição de novo conhecimento tácito na prática. Para Nonaka e Takeuchi (2008), a amplificação do conhecimento é caracterizada não somente no sentido epistemológico, o qual se refere à divisão e relação do conhecimento em tácito e explícito, mas também no ontológico (Figura 2).

Figura 2 - Gráfico das dimensões epistemológica e ontológica da criação do conhecimento

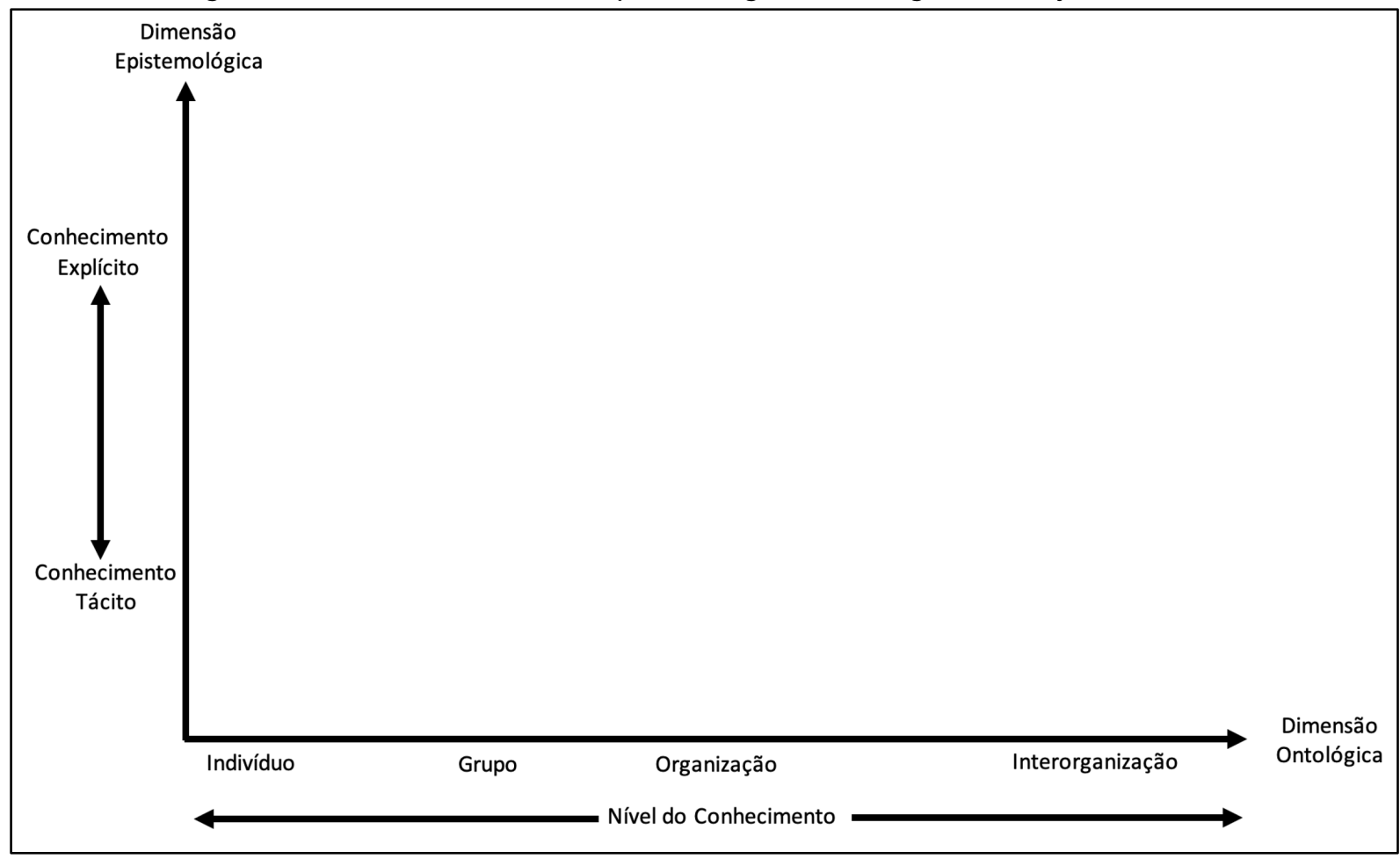

Fonte: Nonaka e Takeuchi (2008, p. 55). 
Na dimensão ontológica, com vistas à ampliação do conhecimento (sentido horizontal da Figura 2), é possível observar que cada modo do processo de conversão traz consigo uma distinta combinação das entidades de criação do conhecimento, de maneira que a socialização aponta para a relação indivíduo para indivíduo; a externalização de indivíduo para o grupo; a combinação do grupo para a organização e a internalização no sentido da organização para o indivíduo (NONAKA; TAKEUCHI, 2008).

\subsection{Gestão do conhecimento}

A globalização é uma realidade que aponta para um mundo caracterizado pelo rápido movimento da informação, especialmente em virtude da incorporação e difusão da internet no final do século XX. Paralelamente, a sociedade é levada a basear-se em uma economia alicerçada no conhecimento, de maneira que o gerenciamento dos recursos humanos que venha a estabelecer vantagem competitiva em um setor específico, esteja condicionado à incorporação e criação de novos conhecimentos (DAVENPORT; PRUSAK, 1998; DRUCKER, 1988).

Em virtude da associação da vantagem competitiva à de criação de conhecimento e inovação em uma economia baseada em informação e conhecimento, muitas corporações passaram a buscar caminhos que potencializassem a efetividade e a eficiência dos processos de criação de conhecimento de seus grupos de trabalho (DIAS; GASSEN; MEDEIROS, 2013; HUANG; WANG, 2002). Discute-se nesse sentido a Gestão do Conhecimento (GC).

Para Carvalho (2012), a GC tem origem nos estudos de Ikujiro Nonaka e Hirotaka Takeuchi. A GC advém da proposta de formalização teórica a respeito da criação do conhecimento, bem como está presente dentro de uma organização por meio de práticas. Ademais, Carvalho (2012, p.47) discorre que "um olhar atento sobre as práticas gerenciais existentes em qualquer organização revelará que muitas delas são práticas de conhecimento".

Mendoza, Bischoff e Willy (2017) destacam que a GC pode possibilitar a colaboração, a criação, a captura, a organização, o acesso e o uso de ativos de informação. Os autores refletem que a programação bem desenvolvida de GC apresenta muitas características valiosas, e possivelmente únicas.

Não obstante, há que se considerar que mesmo em instituições governamentais, onde não há concorrência ou busca por lucratividade, a Gestão do Conhecimento possui seu elevado valor, já que essas instituições são cobradas pela sociedade de maneira a corresponder conforme a excelência disponível no mercado corporativo. Batista (2012, p. 49), observa a GC na administração pública como:

(...) um método integrado de criar, compartilhar e aplicar o conhecimento para aumentar a eficiência; melhorar a qualidade e a efetividade social; e contribuir para a legalidade, impessoalidade, moralidade e publicidade na administração pública e para o desenvolvimento brasileiro.

Os resultados imediatos da GC, de acordo com Batista (2012, p. 68), são “aprendizagem e inovação e, como consequência, o incremento da capacidade de realização individual, da equipe, da organização e da sociedade de identificar, criar, armazenar, compartilhar e aplicar conhecimento". Para Desouza (2011), as organizações não podem operar em seu nível ótimo sem cuidados com a GC, podendo resultar em ineficiência, entrega de produtos e/ou serviços que levarão à insatisfação dos seus clientes, o que em última instância pode levar à falência da organização.

De forma contrária, os resultados alcançados por meio da GC podem proporcionar o aumento da eficiência, melhorar a tomada de decisões nos serviços públicos, ajudar a população a participar efetivamente na tomada de decisões públicas e desenvolver uma força de trabalho competitiva em termos de conhecimento (WIIG, 2002), contribuindo para os princípios norteadores da Administração Pública, como a legalidade, impessoalidade, moralidade, publicidade e a eficiência (BATISTA, 2012).

\subsection{Estudos correlatos - práticas de conversão do conhecimento}


Sharma e Dey (2018) discutem a Gestão do Conhecimento tácito e explícito e apresentam um framework teórico que relaciona os tipos de conhecimento às dimensões culturais (distância do poder, evitar a incerteza, coletivismo, burocracia e adocracia) comuns à maioria dos estudos que envolvem cultura organizacional. Sharma e Dey (2018) explicam que a dimensão cultural "distância do poder" se refere a desigualdade na distribuição do poder e da autoridade dentro das organizações. A dimensão "evitar a incerteza" se refere à medida em que as pessoas se sentem ameaçadas pela incerteza e ambiguidade e tentam evitar tais situações. $\mathrm{O}$ "individualismo/coletivismo" se refere à forma de relacionamento entre o indivíduo e a coletividade em uma determinada sociedade. Determina as relações entre os membros de uma organização. A dimensão da "burocracia" está associada ao trabalho formalizado com procedimentos bem definidos, a autoridade de tomada de decisão é centralizada, os trabalhos são claramente definidos com o planejamento do processo e agrupados de acordo com os departamentos funcionais. A "adocracia" ou organizações de tipo inovador buscam especialistas de uma variedade de áreas funcionais para formar equipes funcionais criativas. A cultura da adocracia pode responder rapidamente às mudanças empregando especialistas qualificados. Sharma e Dey (2018) concluem que a cultura tem uma considerável influência na Gestão do Conhecimento de uma organização.

Maravilhas e Martins (2019) observaram a espiral do conhecimento em Fab Labs de quatro países distintos. Entende-se por Fabs Lab como locais de aprendizagem através da troca de conhecimento entre seus membros. São ambientes que permitem alavancar a inovação utilizando os recursos tecnológicos disponíveis no espaço, estimulando a criatividade de seus participantes e possibilitando o desenvolvimento de produtos e soluções baseados em projetos pessoais de ideação, ou a construção apoiada no conhecimento desenvolvido por outros elementos de forma colaborativa (MARAVILHAS; MARTINS, 2019). Os autores observaram que as diferentes formações dos criadores no espaço de um Fab Lab são potencialmente vantajosas para o compartilhamento e a troca de experiências e conhecimentos que poderá contribuir para todos os participantes.

Magnier-Watanabe e Benton (2017) examinaram o papel do conhecimento tácito e explícito na tradução da inovação de gestão em desempenho em empresas japonesas. Observou-se que não houve efeito direto da inovação em gestão sobre o desempenho das empresas, e que, em vez disso, tanto o conhecimento tácito quanto o explícito mediaram totalmente a relação entre a inovação em gestão e o desempenho da empresa. Embora os programas de inovação em gestão por si só não tenham aumentado diretamente o desempenho da empresa, o alinhamento desses programas com as iniciativas de GC melhorou o desempenho. Os resultados de Magnier-Watanabe e Benton (2017) aludem à necessidade de que as organizações devem focar ou destacar o conhecimento que pretende criar ou partilhar. Deve-se estabelecer uma estratégia clara de conhecimento que envolva funcionários e a criação de conhecimento tácito e explícito. Essa prática é especialmente importante no mundo atual de mudanças onipresentes em que novos conhecimentos são necessários para lidar com o ambiente em mudança.

\section{MATERIAL E MÉTODO}

O estudo contou com um total de três sujeitos, quantidade essa que totaliza todo o efetivo de técnicos do Laboratório de Leitura e Análise de Dados de Gravadores de Voo (LABDATA) da Força Aérea Brasileira (FAB). Como o número de sujeitos da pesquisa era reduzido (três técnicos), optou-se por uma abordagem qualitativa com a coleta de dados realizada por meio de entrevistas semiestruturadas (GODOY, 2006) e uma lógica indutiva. A análise dos dados se deu pela técnica de análise de conteúdo, proposta por Bardin (2016). Por intermédio de assertivas desenvolvidas na pesquisa de Huang e Wang (2002), foram adaptadas questões que traduzem as perspectivas dos quatro modos de conversão de conhecimento (modelo SECI). Utilizou-se como base estruturante da ferramenta de coleta de dados o estudo de Huang e Wang (2002) por sua semelhança com os objetivos deste trabalho.

Segundo Godoy (2006), a entrevista semiestruturada visa compreender os significados atribuídos pelos entrevistados às questões e situações relativas ao tema analisado. Paralelamente, a entrevista semiestruturada 
não necessita vincular-se a uma entrevista rígida, ou seja, ela é aberta a um roteiro livre, onde o entrevistado possa expressar suas percepções sem seguir com rigidez o que foi inicialmente definido pelo entrevistador. Bardin (2016) teoriza a técnica de análise conteúdo da seguinte maneira:

Um conjunto de técnicas de análise das comunicações visando obter, por procedimentos sistemáticos e objetivos de descrição do conteúdo das mensagens, indicadores (quantitativos ou não) que permitam a inferência de conhecimentos relativos às condições de produção/recepção (variáveis inferidas) dessas mensagens (BARDIN, 2016, p. 48).

Nesse contexto, para Bardin (2016), o domínio da análise de conteúdo reflete todas as iniciativas que, a partir de técnicas parciais mais complementares, venha a consistir na explicitação e sistematização do conteúdo e de sua expressão. A técnica permite ao analista criar mecanismos de operações analíticas adaptáveis à natureza do material bem como ao tema que busca resolver. Segundo Bardin (2016), as fases da análise de conteúdo consistem na pré-análise, exploração do material e no tratamento dos resultados obtidos. A fase da pré-análise é aquela que trata da organização, correspondendo a um período de intuições, já objetivando tornar as ideias iniciais operacionalizadas e sistematizadas. Dessa forma, cabe ao pesquisador organizar o material levantado de maneira a facilitar a sistematização das informações principais. A segunda fase, exploração do material, trata da aplicação sistemática das decisões tomadas, a qual será baseada na técnica de análise de entrevista. As entrevistas ocorreram na forma verbal, que por sua vez, foram transcritas na íntegra, levando-se em consideração os estímulos dos entrevistados.

Por meio da análise foi possível estruturar os dados brutos e organizar tabelas associadas ao roteiro de entrevista. Por conseguinte, concatenou-se as informações ressaltando as recorrências e destacando os pontos importantes à luz do referencial teórico apresentado. Para o tratamento dos resultados obtidos, Bardin (2016) recomenda que o pesquisador realize interpretações e inferências associadas ao objetivo previsto, atendo-se inclusive às possíveis descobertas inesperadas.

Para que os dados fossem ordenadamente coletados de acordo com os modos de conversão do conhecimento proposto por Nonaka e Takeushi (2008), destaca-se o Quadro 2.

Quadro 2 - Roteiro de entrevista

\section{Modo de conversão de conhecimento - Internalização:}

1) Quando você ouve uma nova ideia ou conceito, qual é o seu comportamento?

2) Quais mecanismos de comunicação você utiliza para melhor compreender os pensamentos dos outros?"

3) O que você faz para se certificar de que aquilo que você entende confere com o que interlocutor entende?

4) O que você faz para se certificar de que aquilo que foi dito ao interlocutor, foi entendido corretamente?

Modo de conversão de conhecimento - Externalização:

5) Quando seus colegas do LABDATA não conseguem te compreender, você utiliza de algum recurso para os ajudá-los na compreensão?

6) O que faz para transcrever pensamentos não organizados em ideias concretas?

7) O que faz para descrever termos profissionais e técnicos de forma a facilitar a comunicação com o LABDATA?

8) O que você faz para expressar conceitos abstratos?

9) Como você consegue explicar conceitos abstratos aos seus colegas?

10) Quando alguém não expressa com clareza aquilo que possui em mente, como você age?

\section{Modo de conversão de conhecimento - Socialização:}

11) Com vistas às suas experiências no setor, como você age nas discussões do LABDATA?

12) Como é a dinâmica de seus compartilhamentos de experiências de vida e de trabalho no LABDATA?

13) Como se dá sua percepção perante as opiniões, pensamentos e outras informações do grupo durante as discussões do LABDATA?

14) Como você pontua sua participação nas discussões do LABDATA. É ativa? Se sim, como?

15) Como você se percebe com relação ao encorajamento de seus colegas quanto a expressarem seus próprios pensamentos?

\section{Modo de conversão de conhecimento - Combinação:}

16) O que você faz para facilitar a comunicação durante discussões em que as ideias não estejam muito bem alinhadas/estruturadas? 


\begin{tabular}{l}
$\begin{array}{l}\text { 17) Em que medida sua experiência é utilizada para solucionar os problemas } \\
\text { do LABDATA? }\end{array}$ \\
\hline 18) Como você lida, em termos de registro de informações, após cada evento novo que você vivência? \\
\hline 19) Como você lida com os pensamentos explicitados pelos outros em sua mente durante uma discussão? \\
\hline $\begin{array}{l}\text { 20) Como você se defronta diante de novas informações bem como com conexões de conhecimentos novos } \\
\text { e antigos? }\end{array}$ \\
\hline 21) Como você lida com a organização de conceitos ambíguos em uma estrutura? \\
Fonte: Adaptado de Huang e Wang (2002).
\end{tabular}

O Quadro 2 destaca a ordem em que o roteiro de entrevista foi aplicado de acordo com os modos de conversão do conhecimento. Ressalta-se que os entrevistados não tiveram conhecimento de tais divisões e que o estudo está aprovado no Comitê de Ética em Pesquisa (CEP) sob o registro 96852518.7.0000.5111.

\section{ANÁLISES E DISCUSSÕES}

O efetivo total de militares que compõe o LABDATA é bastante restrito em termos quantitativos, sendo apenas 3 (três) militares. De maneira a não expor as identidades dos entrevistados, esses foram nomeados como E1, E2 e E3. O Quadro 3 apresenta os dados sociodemográficos dos respondentes.

Quadro 3 - Características dos respondentes

\begin{tabular}{|l|c|c|c|}
\hline & E1 & E2 & E3 \\
\hline $\begin{array}{l}\text { Tempo de serviço no } \\
\text { LABDATA }\end{array}$ & 6 ANOS & 4 ANOS & ANOS \\
\hline $\begin{array}{l}\text { Escolaridade / Formação } \\
\text { Acadêmica }\end{array}$ & $\begin{array}{c}\text { Superior /Analista de } \\
\text { sistemas }\end{array}$ & $\begin{array}{c}\text { Superior /Engenheiro da } \\
\text { computação }\end{array}$ & $\begin{array}{l}\text { Ensino médio / } \\
\text { Graduando em } \\
\text { engenharia eletrônica }\end{array}$ \\
\hline Idade & 50 anos & 26 anos & 28 anos \\
\hline
\end{tabular}

Fonte: Elaborado pelos autores (2019).

De forma a propiciar uma análise didaticamente lógica, a discussão dos resultados foi realizada separadamente quanto às divisões dos modos de conversão do conhecimento.

\subsection{Modo de conversão de conhecimento - Internalização}

Retomando os conceitos de Nonaka e Takeuchi (2008), a internalização é o processo de conversão do conhecimento explícito para tácito por meio da absorção de conhecimentos, sendo esses possíveis por vários meios como leitura, prática individual, consulta de registros de conhecimentos, dentre outros.

No decorrer da entrevista, foi possível verificar que o grupo tem uma postura aberta quantos às informações proferidas pelos seus pares, por ocasião do recebimento de uma nova ideia ou conceito. A exemplo, foi relatada a importância de se avaliar atentamente a informação recebida, considerando que as novas ideias e conceitos podem ser importantes para soluções. Tal característica reforça as capacidades de reinterpretação e reexperimentação individual das vivências práticas, conforme relatos: "Eu avalio aquela ideia e faço o meu comentário pessoal, citando, quando necessário, a minha opinião." (E1); e "Paro para prestar atenção e absorver o máximo de entendimento da ideia ou conceito." (E2).

Como as atividades do setor não podem ser plenamente padronizadas, já que tratam também da necessidade de inovar e criar mecanismos de soluções inopinadas, em especial para extração de dados de gravadores de voo danificados, observa-se uma postura receptiva à aprendizagem e criatividade:

Tendo em vista que o trabalho exercido no LABDATA é bem peculiar e as soluções não são triviais, faz-se necessário receber novas ideias ou conceitos, que ainda não foram explorados para sanar os problemas da seção. (E3)

Ainda com relação ao modo de conversão de conhecimento de internalização, observa-se a migração do conhecimento explícito para o conhecimento tácito nos momentos em que integrantes da equipe utilizam 
mecanismos de comunicação para melhor compreender e assimilar os pensamentos de seus pares, como apresentam os relatos a seguir:

Comunicação oral e escrita. Ou seja, questiono sobre dúvidas a respeito do assunto e procuro fazer anotações de exemplos citados. (E1)

Comunicação oral. O setor utiliza a técnica de brainstorming, que tem a premissa de explorar a capacidade criativa do grupo por meio de uma tempestade de ideias, a fim de gerar soluções inovadoras para um determinado projeto. (E3)

De forma a corroborar com o incremento da internalização, foram relatadas ainda determinadas atitudes diante dos interlocutores, quais sejam:

Eu cito exemplos do meu ponto de vista para ter a certeza de que estamos na mesma linha de raciocínio. (E1)

Pergunto a respeito do assunto com exemplificações para certificar-me do entendimento. (E2)

Retiro todas as minhas dúvidas inerentes ao assunto, e exemplifico-o para ter plena convicção que estamos convergindo. (E3)

Paralelamente, quando na posição de interlocutor, percebe-se atenção do grupo em certificar-se do entendimento correto por parte do ouvinte:

Eu faço perguntas referentes ao assunto e gosto de citar vários exemplos práticos do dia a dia para assegurar o entendimento. (E1)

Pergunto se foi entendido ou se foi gerada alguma dúvida quanto ao entendimento. (E2)

Peço-lhe para retirar todas as suas dúvidas, e exemplificar o que foi abordado. (E3)

Considerando-se ainda as interações mencionadas pelo grupo, em especial as verbais, é válido destacar a citação de Nonaka e Takeuchi (2008, p. 67), ao explorarem a perspectiva de internalização:

A internalização é um processo de incorporação do conhecimento explícito em conhecimento tácito. Está intimamente ligada ao "aprender fazendo" ... Quando as experiências através da socialização, externalização, e combinação são internalizadas nas bases de conhecimento tácito do indivíduo, na forma de modelos mentais compartilhados ou know-how técnico, tornam-se um patrimônio valioso.

Nonaka e Takeuchi (2008, p. 67), afirmam que: “(...) para que o conhecimento explícito seja tácito, ajuda se ele for verbalizado ou diagramado em documentos, manuais ou relatos orais. A documentação ajuda os indivíduos a internalizarem o que vivenciaram...". Nesse sentido, conforme relatado nas entrevistas, pôdese averiguar que a equipe do LABDATA explora bem a internalização por meio da comunicação oral, entretanto, não aponta para uma exploração de elevado nível de transferência de conhecimento explícito para tácito por meio da visualização e leitura sistemática de documentações técnicas. Isso posto, o Quadro 4 compila os resultados positivos e negativos das características de internalização do grupo.

Quadro 4 - Quadro resumo internalização.

\begin{tabular}{|l|l|}
\hline \multicolumn{1}{|c|}{ Destaque Positivo } & \multicolumn{1}{|c|}{ Destaque Negativo } \\
\hline $\begin{array}{l}\text { Boa comunicabilidade oral, reinterpretação e } \\
\text { reexperimentação individual das vivências práticas. }\end{array}$ & $\begin{array}{l}\text { Pouca visualização e leitura sistemática de } \\
\text { documentações técnicas. }\end{array}$ \\
\hline
\end{tabular}

Fonte: Elaborado pelos autores (2019).

Para Mohsen Allameh et al. (2014), a concepção e execução de mecanismos de documentação para constituir um registo sistemático dos conhecimentos e experiências dos profissionais, bem como a aplicação adequada de Sistemas de Informação Gerencial (SIG), podem ser consideradas como aplicações fundamentais para reforçar o compartilhamento de conhecimento e a melhoria do desempenho organizacional, especialmente de processos associados à GC.

Na sequência, analisar-se-á o modo de conversão do conhecimento externalização. 


\subsection{Modo de conversão de conhecimento - Externalização}

Conforme definição de Nonaka e Takeuchi (2008, p. 62), "a externalização é um processo de articulação do conhecimento tácito em conceitos explícitos." Ao mesmo tempo, retomando uma das formas abordadas de externalização, Nonaka e Takeuchi (2008, p. 62), consideram que "a metáfora é uma forma de perceber ou entender intuitivamente uma coisa, imaginando outra coisa simbolicamente". Logo, a externalização relaciona-se em especial ao conteúdo verbalizado, meio pelo qual o conhecimento tácito se converte em explícito.

Nesse sentido, observou-se que há o uso de alguns recursos para favorecer uma compreensão mais adequada daquilo que se é explanado, como: desenhos, pesquisas na internet, gráficos, equações e metáforas, como observado nos relatos: "Dependendo do assunto, utilizo ferramentas como desenhos, pesquisas na internet e exemplificações para clarear a ideia" (E2); "Costumo utilizar as seguintes ferramentas para compreensão: gráficos, equações, desenhos e metáforas da vida" (E3).

Ao mesmo tempo, para que pensamentos não organizados possam ser apresentados na forma de ideias concretas são utilizadas diferentes técnicas, como apontado nos relatos:

Eu as lanço como tópicos e depois procuro organizá-las em uma ordem cronológica. (E1)

Escrever esses pensamentos, mesmo que de forma não organizada, analisar a coerência e pertinência das ideias e colocar em ordem para conseguir concretizar. (E2)

Utilizo um diagrama de blocos, que visa detalhar a entrada, o processo e a saída de qualquer ideia não concretizada. (E3)

Por meio de mecanismos específicos para externalização, o grupo utiliza recursos de modelagem de sistemas computacionais (diagrama de blocos, por exemplo), descrições em papel, desenhos e experiências vividas, especialmente quando se trata de conceitos mais abstratos. Pode-se observar que o processo de externalização é bem empregado no laboratório, já que as respostas atestam a assertiva de Nonaka e Takeuchi (2008, p. 62) em que "o modo de externalização da conversão do conhecimento é visto, tipicamente, no processo da criação de conceitos e é desencadeado pelo diálogo ou pela reflexão coletiva". O Quadro 5 compila os resultados positivos e negativos das características de externalização do grupo.

Quadro 5 - Quadro resumo externalização.

\begin{tabular}{|l|l|}
\hline \multicolumn{1}{|c|}{ DESTAQUE POSITIVO } & \multicolumn{1}{|c|}{ DESTAQUE NEGATIVO } \\
\hline $\begin{array}{l}\text { Exposição de conhecimento tácito por meio de gráficos, } \\
\text { equações, desenhos, metáforas e analogias e exemplos dos } \\
\text { indivíduos para com o grupo. }\end{array}$ & $\begin{array}{l}\text { Não foram observadas a presença de } \\
\text { características negativas na etapa de } \\
\text { externalização. }\end{array}$ \\
\hline
\end{tabular}

Fonte: Elaborado pelos autores (2019).

Acredita-se que o fato da análise da etapa de externalização não ter apresentado características negativas se deve ao pequeno número de envolvidos, colocalização geográfica e facilidade do ambiente para troca de experiências. D'Arisbo et al. (2013) considera que nessa etapa são utilizados conhecimentos que provêm da aprendizagem formal e informal. Há espaço tanto para o processo indutivo quanto dedutivo e nos casos em que há mais liberdade para o profissional, ele se sente mais confortável, utilizando mais da sua experiência.

\subsection{Modo de conversão de conhecimento - Socialização}

Segundo Nonaka e Takeuchi (2008, p. 60), "a socialização é um processo de compartilhamento de experiências e, com isso, de criação de conhecimento tácito, tais como os modelos mentais e as habilidades técnicas compartilhadas". Nonaka e Takeuchi (2008, p.60), complementam que "a chave para a aquisição do conhecimento tácito é a experiência. Sem alguma forma de experiência 
compartilhada é extremamente difícil que uma pessoa se projete no processo de raciocínio de outro indivíduo."

Nesse sentido, a socialização fundamenta-se especialmente no diálogo e na relação (interação) do grupo, tratando-se da conversão de conhecimentos tácito para tácito, passando-se a informação de indivíduo para indivíduo. Nonaka e Takeuchi (2008, p. 43), em um exemplo, retrata que um aprendiz de padeiro "aprendeu suas habilidades tácitas através da observação, imitação e prática. Elas tornaram-se parte da sua própria base de conhecimento tácito. Colocando de outra forma, ela foi "socializada" no artesanato". Logo, observa-se que a socialização pode ocorrer sem a presença de um ato formal, mas basicamente por meio de modelos mentais e habilidades técnicas que agreguem a transmissão do conhecimento.

Tendo em vista as experiências no LABDATA, as atitudes durante as discussões acerca das atividades, foram descritas das seguintes maneiras:

Se tenho conhecimento sobre o assunto, exponho as minhas ideias. Caso contrário, ouço com atenção e faço pergunta quando tenho algum tipo de dúvida. (E1)

Exponho o meu ponto de vista quando considero que agregará valor ao setor e contesto opiniões quando não vejo como uma melhoria / progresso para o setor ou não compreendo alguma ideia. (E2)

Estou próximo dos meus 7 anos no setor, sou o militar que possui mais tempo exercendo a função, no entanto, não possuo nenhuma resistência às ideias que não foram fomentadas por mim. Tenho plena confiança no trabalho por eles exercido e acredito fielmente no potencial de todos integrantes do grupo. (E3)

O grupo trata, ainda, da dinâmica de seus compartilhamentos de experiências de vida e de trabalho no LABDATA, relatando que para a adoção de ideias faz-se necessário ter "mente aberta" e um debate livre, considerando-se ainda que a liberdade de expor as ideais de forma descontraída permite uma visão mais ampla da perspectiva de todos os integrantes do setor.

Constatou-se por meio dos relatos de todos os entrevistados um ambiente harmonioso e reciprocamente respeitoso entre os integrantes do grupo, características essas que contribuem para um sadio e intenso compartilhamento de experiências.

É totalmente alinhada com o grupo do LABDATA, pelo fato de estar a favor do crescimento do setor o que irá otimizar, indiscutivelmente, o nosso trabalho, melhorando o ambiente de atividade afim. (E1)

Sempre atenta, buscando absorver o máximo de informação, novas ideias e experiências e principalmente de informações implícitas. (E2)

Sou muito receptivo e flexível às opiniões e pensamentos do grupo. (E3)

As participações do grupo em suas discussões mostram-se intensa, próxima e ativa, o que é corroborado pelo fato de ser um grupo pequeno, bem como seus integrantes já se conhecerem por aproximadamente 7 (sete) anos e possuírem relativa experiência nas atividades. Ao mesmo tempo, indicam que a chefia atual proporciona liberdade de manifestações de pensamento, o que corrobora com o entrosamento e a externalização de ideias. Isso posto, depreende-se que as atividades do grupo corroboram para a manifestação da conversão de conhecimento do modo Socialização. O Quadro 6 compila os resultados positivos e negativos das características de socialização do grupo.

Quadro 6 -Quadro resumo socialização

\begin{tabular}{|l|l|}
\hline \multicolumn{1}{|c|}{ DESTAQUE POSITIVO } & \multicolumn{1}{c|}{ DESTAQUE NEGATIVO } \\
\hline $\begin{array}{l}\text { Aprendizado de habilidades tácitas através da } \\
\text { observação, imitação e prática. }\end{array}$ & $\begin{array}{l}\text { Não observada a presença de característica } \\
\text { negativa no grupo. }\end{array}$ \\
\hline
\end{tabular}

Fonte: Elaborado pelos autores (2019).

O ambiente em que os envolvidos atuam, as experiências empíricas e a postura da chefia facilitam o processo de socialização. Pee e Kankanhalli (2016) observaram que a experiência profissional de funcionários 
aumenta a eficácia dos recursos físicos de GC enquanto a estrutura organizacional pode ter um efeito supressor. Os destaques do Quadro 6 têm certa relação aos resultados apontados por Maravilhas e Martins (2019). A formação acadêmica distinta (Quadro 3) dos profissionais do LABDATA são potencialmente vantajosas para a partilha e troca de experiências e conhecimentos que podem enriquecer as atividades do grupo do LABDATA.

\subsection{Modo de conversão de conhecimento - Combinação}

Nonaka e Takeuchi (2008, p. 65) consideram que a etapa de combinação do processo SECl "envolve a combinação de diferentes corpos de conhecimento explícito. Os indivíduos trocam e combinam o conhecimento por meio de documentos, reuniões, conversas telefônicas...". Logo, tal competência associa a capacidade de combinar conhecimentos prévios, relacionando-os de forma que sejam desenvolvidos novos conhecimentos. O modo de conversão de conhecimento de combinação, refere-se, portanto, à migração de conhecimento explícito para explícito.

A primeira pergunta do roteiro de entrevista associado à combinação tratou da tentativa de melhorar a estruturação de ideias de forma a expô-las nas discussões. Observou-se pelas respostas que são solicitadas explicações ao longo dos diálogos, bem como a tentativa de melhor fundamentação dos conceitos e flexibilidade na postura diante das informações recepcionadas. Foram levantadas ainda informações atinentes à relação das experiências individuais diante das soluções de problemas afetos ao setor, conforme relatos:

Quando percebo que já vivenciei aquela situação antes e me lembro da solução que utilizei, coloco em prática também naquela ocasião, repassando aos meus colegas do setor. (E1)

Eu sou a pessoa que possui menos experiência e capacitação em gravadores de voo no setor. Porém, busco trazer ideias e conhecimentos adquiridos na área de informática (minha especialidade). (E2)

A minha experiência é muito utilizada. No entanto, se a mesma não fosse somada aos conhecimentos dos meus colegas nenhum problema teria sido resolvido. (E3)

Por tratar-se especificamente de explicitações, parte do teor dos questionamentos acerca do tema combinação aprofunda-se também nos registros de informações após cada evento vivenciado, os quais remeteram às seguintes respostas:

Essa é uma prática ainda não adotada devido ao surgimento de novas tarefas no laboratório (contribuindo para que caia no esquecimento o registro da atividade), mas reconhecemos a necessidade desse procedimento tendo em vista que após um longo período depois de sua ocorrência o mesmo poderá se repetir. (E1)

Existem procedimentos para registrar ocorrências com gravadores de voo no LABDATA. Todavia, o procedimento operacional que é baseado em Manuais de fabricantes, experiências do dia a dia e também conhecimentos tácitos não possui uma regra para ser registrado. Então, acabo registrando aquilo que eu acho importante para o trabalho no Setor. (E2)

Confesso que sou falho nesse aspecto, pois muitos processos ainda estão tão somente na minha cabeça. Por vezes esqueço de registrar o que foi feito, e com isso dificulto o serviço se houver um problema recorrente. (E3)

A equipe demonstrou senso crítico ao recepcionar novas informações do grupo, já que buscam realizar críticas construtivas e organizam seus pensamentos de modo a identificar ideias que acrescentem um conhecimento positivo para o trabalho.

Acredito que somente há evolução quando estamos dispostos a novas mudanças. Por isso que procuro me inteirar de um assunto novo que é lançado no meu trabalho. (E1)

Analiso a informação criticamente, costumo pesquisar se eu não possuo conhecimento no assunto e tento relacionar com conhecimentos antigos para um melhor entendimento das informações, ou até mesmo atualizações de conceitos. (E2)

As novas informações e a conexão de conhecimento são fatores preponderantes para a minha evolução profissional, com isso, agrego-os em minha realidade e quando houver possibilidade. (E3) 
Observou-se a necessidade de aperfeiçoamento do agrupamento de registros documentais (escritos) por parte do grupo e uma deficiente rotina prática, a qual debilita a capacidade da equipe de perpetuar parte de suas criações, ideias e aprendizagens, com consequente influência negativa no potencial da combinação do conhecimento. O Quadro 7 compila os resultados positivos e negativos das características de combinação do grupo.

Quadro 7 - Quadro resumo combinação.

\begin{tabular}{|l|l|}
\hline \multicolumn{1}{|c|}{ Destaque Positivo } & \multicolumn{1}{c|}{ Destaque Negativo } \\
\hline $\begin{array}{l}\text { Senso crítico ao recepcionar novas informações do grupo, já } \\
\text { que buscam realizar críticas construtivas e organizam seus } \\
\text { pensamentos de modo a identificar ideias que acrescentem um } \\
\text { conhecimento positivo para o trabalho. }\end{array}$ & $\begin{array}{l}\text { Necessidade de se aperfeiçoar o } \\
\text { agrupamento de registros documentais } \\
\text { (escritos) por parte do grupo. }\end{array}$ \\
\hline
\end{tabular}

Fonte: Elaborado pelos autores (2019).

Acredita-se que devido ao nível de integração e informalidade entre a equipe, procedimentos burocráticos associados à etapa de combinação do conhecimento são observados como secundários e desconsiderados. Cordeiro, Oliveira e Sampaio (2016) argumentam que a integração do conhecimento em diferentes níveis na organização pode gerar novos processos e ampliar a capacidade de inovação. Depreendese, portanto, que os modos de externalização e de socialização, no contexto avaliado, favorecem mais à conversão de conhecimento que os modos de internalização e combinação, os quais possuem destaques negativos, conforme Quadro 8.

Quadro 8 - Quadro resumo dos resultados

\begin{tabular}{|l|l|l|}
\hline \multicolumn{1}{|c|}{$\begin{array}{c}\text { Modo de } \\
\text { conversão }\end{array}$} & \multicolumn{1}{|c|}{ Destaque positivo } & \multicolumn{1}{|c|}{ Destaque negativo } \\
\hline Internalização & $\begin{array}{l}\text { Boa comunicabilidade oral, reinterpretação e } \\
\text { reexperimentação individual das vivências práticas. }\end{array}$ & $\begin{array}{l}\text { Pouca visualização e leitura } \\
\text { sistemática de documentações } \\
\text { técnicas. }\end{array}$ \\
\hline Externalização & $\begin{array}{l}\text { Exposição de conhecimento tácito por meio de } \\
\text { gráficos, equações, desenhos, metáforas e analogias } \\
\text { e exemplos dos indivíduos para com o grupo. }\end{array}$ & $\begin{array}{l}\text { Não observada a presença de } \\
\text { característica negativa no } \\
\text { grupo. }\end{array}$ \\
\hline Socialização & $\begin{array}{l}\text { Aprendizado de habilidades tácitas através da } \\
\text { observação, imitação e prática. }\end{array}$ & $\begin{array}{l}\text { Não observada a presença de } \\
\text { característica negativa no } \\
\text { grupo. }\end{array}$ \\
\hline Combinação & $\begin{array}{l}\text { Senso crítico ao recepcionar novas informações do } \\
\text { grupo, já que buscam realizar críticas construtivas e } \\
\text { organizam seus pensamentos de modo a identificar } \\
\text { ideias que acrescentem um conhecimento positivo } \\
\text { para o trabalho. }\end{array}$ & $\begin{array}{l}\text { Necessidade de se aperfeiçoar } \\
\text { o agrupamento de registros } \\
\text { documentais (escritos) por } \\
\text { parte do grupo. }\end{array}$ \\
\hline
\end{tabular}

Fonte: Elaborado pelos autores (2019).

Com o objetivo de proporcionar maior validade externa aos resultados da presente pesquisa, considerou-se o estudo de Begnini (2015), realizado em uma Instituição Federal de Ensino Superior brasileira. Begnini (2015) concluiu que "os modos de conversão - socialização e externalização - parecem mais consolidados, enquanto - combinação e internalização - parecem necessitar de amadurecimento" (BEGNINI, 2015, p. 603).

Pode-se observar que tanto a presente pesquisa quanto a de Begnini (2015) apresentaram os modos de conversão de conhecimento de combinação e de internalização carecendo de aprimoramento. Tais resultados podem indicar limitações nesses modos de conversão do conhecimento no âmbito da Administração Pública Federal brasileira. Observa-se que ambos os modos estão associados a práticas sistemáticas e disciplinadas que muitas vezes podem ser substituídas por adaptações na forma de documentação ou na utilização da criatividade para solução de problemas em detrimento a documentos formalizados, como manuais. Essas características são observadas por Freitas (2007) e Figueiredo (2007) como traços culturais brasileiros que infuenciam nas práticas organizacionais. Sharma e Dey (2018) consideraram 
que a cultura pode ter considerável influência em práticas que envolvem a Gestão do Conhecimento. Observase nos resultados desta pesquisa que a dimensão burocrática, destacada por Sharma e Dey (2018), influenciou os modos de conversão do conhecimento de combinação e internalização.

Por fim, considerando o estudo de Magnier-Watanabe e Benton (2017), os profissionais do LABDATA podem desenvolver as práticas de GC no setor ao estabelecer estratégias claras na forma como os conhecimentos tácitos e explícitos do grupo serão criados e geridos.

\section{CONSIDERAÇõES FINAIS}

Retomando a pergunta inicial do presente trabalho, "o comportamento do efetivo do LABDATA aplica práticas para a criação, aquisição, integração e compartilhamento do conhecimento de acordo com o que preconiza o campo da Gestão do Conhecimento?". Foi possível constatar que as práticas de GC da equipe do LABDATA têm colaborações distintas a depender do tipo do modo de conversão. $O$ grupo é pequeno e todos trabalham no mesmo espaço físico. Tais características reforçam um bom entrosamento da equipe, somandose como elementos que favorecem a aprendizagem. As entrevistas permitiram observar um ambiente harmonioso e respeitoso entre o grupo, características que agregam ao compartilhamento de experiências e conhecimento, reforçando positivamente as capacidades de externalização e de socialização do grupo.

Em contrapartida, o grupo demonstrou fragilidade na atenção às documentações das aprendizagens de suas atividades, as quais reduzem suas capacidades de perpetuação e compartilhamento de descobertas, bem como as inovações relacionadas a seus serviços. Tais particularidades comprometem parcialmente as competências do setor à luz da teoria da espiral do conhecimento, em especial sob os fundamentos das dimensões de internalização e de combinação. Características culturais do brasileiro podem influenciar os processos de internalização e combinação pelo fato dessas etapas exigirem práticas sistemáticas, destoantes dos traços culturais nacionais apontados pela literatura como associados à flexibilidade. Ressalta-se que não obstante à identificação das fragilidades supracitadas, há de se considerar que tais particularidades não excluem a presença das dimensões de internalização e de combinação no grupo. Tal fato se dá em virtude da presença de destaques positivos, como boa comunicabilidade oral, reexperimentação individual das vivências práticas e senso crítico positivo.

As contribuições deste estudo podem ser observadas em dois planos, o acadêmico e o organizacional. No plano acadêmico, contribuiu para ampliar os estudos que envolvem a Gestão do Conhecimento na Administração Pública Federal (APF) brasileira e lançar luz sobre a temática "práticas de conversão do conhecimento" em órgãos da APF, especialmente, aqueles que contam com um considerável acúmulo de conhecimento tácito em seus integrantes. No plano organizacional, o estudo permitiu observar debilidades no processo de conversão do conhecimento no âmbito do LABDATA que, em momento futuro, serão utilizados como fundamentos para novas práticas de GC no setor. Acreditamos que as discussões teóricas entre os resultados deste trabalho e a literatura pertinente pode incentivar o desenvolvimento de estratégicas organizacionais no âmbito da APF que envolvam práticas de conversão do conhecimento com o objetivo de melhorar o desempenho dos serviços prestados aos cidadãos. Refletimos ainda que, diante do atual objetivo do Estado em racionalizar recursos nos órgãos governamentais, a adequada aplicação de práticas de GC podem auxiliar na consecução desse objetivo.

Tendo em vista as fraquezas demonstradas nos aspectos de elaborações documentais relacionadas às aprendizagens do grupo, em especial quando relacionadas às inovações e criações de novas técnicas de abordagem para extração de dados de gravadores de voo, este trabalho requer um maior aprofundamento com respeito às possíveis ferramentas administrativas que permitam padronizar novas ações gerenciais da equipe. Sugere-se como pesquisas futuras estudos que envolvam a GC em outros órgãos da APF, em especial as organizações militares. 


\section{REFERÊNCIAS}

BARDIN, Lawrence. Análise de conteúdo. São Paulo: Edições 70, 2016.

BATISTA, Fábio. Ferreira. Modelo de gestão do conhecimento para a administração pública brasileira: como implementar a gestão do conhecimento para produzir resultados em benefício do cidadão. Brasília: Ipea, 2012.

BEGNINI, Sergio. A conversão do conhecimento em uma Universidade Federal com base em Nonaka e Takeuchi. Revista Eletrônica em Gestão, Educação e Tecnologia Ambiental, Santa Maria, v. 19, n. 3, p. 603614, set./dez. 2015. DOI: 105902/2236117018572

CARVALHO, Fábio Câmara Araújo de. Gestão do Conhecimento. São Paulo: Pearson, 2012.

BRASIL. Ministério da Defesa. Comando da Aeronáutica. Investigação e Prevenção de Acidentes Aeronáuticos, 2017. Disponível em: http://www2.fab.mil.br/cenipa/index.php/legislacao/nsca-norma-dosistema-do-comando-da-aeronautica?download=112:nsca3-13. Acesso em: 22 abr. 2019.

CORDEIRO, Marcelo; OLIVEIRA Mírian; SAMPAIO, Claudio. O papel da Gestão do Conhecimento na Orientação para Aprendizagem no contexto da Inovação: uma proposição teórica. Espacios, v. 37, n. 34, p. 29-29, 2016.

D'ARISBO, Anelise. et al. Criação de conhecimento sob a ótica da aprendizagem organizacional em uma empresa criativa. Revista Administração UFSM, v. 6, n. 3, p. 527-545, 2013.

DAVENPORT, Thomas. H.; PRUSAK, Laurence. Conhecimento empresarial. Rio de Janeiro: Campus, 1998.

DESOUZA, Kevin. C. Knowledge management: An introduction. New York: Neal-Schuman Publishers, Inc, 2011.

DIAS, Ana Rita Schneider; GASSEN, Taísa Bulegon; MEDEIROS, Flaviani Souto Bolzan. Gestão do Conhecimento: o caso de uma cooperativa de crédito. Gestão \& Conhecimento, v. 7, n. 2, p. 9-27, jul./dez. 2013.

DRUCKER, Peter. The Coming of the new organization. Harvard Business Review, v. 66, n. 1, p. 45-53, 1988.

FIGUEIREDO, Eliézer de Oliveira. Olhando a Gestão da fila sob a perspectiva da cultura organizacional: Abordagem com intenção etnográfica em agência bancária da zona oeste do Rio de Janeiro. Programa de Pós-Graduação em Gestão e Estratégia em Negócios (Dissertação de Mestrado). Universidade Federal Rural do Rio de Janeiro. 2007. Disponível em: https://tede.ufrrj.br/jspui/handle/tede/979. Acesso em: 23 abr. 2019.

FREITAS, A. B. Traços Brasileiros para uma análise Organizacional. In: MOTTA, F. P.; CALDAS, M. P. (org.). Cultura organizacional e cultura brasileira. 1. ed. São Paulo: Atlas, 2007. p. 38-54.

GODOY, Arilda Schmidt. Estudo de caso qualitativo. In: GODOY, Chistiane Kleinübing et al. (org.). Pesquisa Qualitativa em estudos organizacionais: paradigmas, estratégias e métodos. São Paulo: Saraiva, 2006, p. 115-146.

HASS, Martine. R.; HANSEN, Morten. T. Different knowledge, different benefits: toward a productivity perspective on knowledge sharing in organizations. Strategic Management Journal, v. 28, n. 11, p. 11331153, 2007. DOI: 10.1002/smj.631

HUANG, J.; WANG, S. Knowledge conversion abilities and knowledge creation and innovation: a new perspective on team composition. In:EUROPEAN CONFERENCE ON ORGANIZATIONAL KNOWLEDGE, LEARNING AND CAPABILITIES, 3., 2002, Athens. Proceedings European Conference on Organizational Knowledge, Learning and Capabilities. Athens: Astir Palace Hotel, 2002. p. 1-18. 
MOHSEN ALLAMEH, Sayyed. M. et al. Developing a model for examining the effect of tacit and explicit knowledge sharing on organizational performance based on EFQM approach. Journal of Science and Technology Policy Management, v. 5, n. 3, p. 265-280, 2014. DOI: 10.1108/JSTPM-05-2014-0025

NONAKA, I.; TAKEUCHI, H. Gestão do conhecimento. Porto Alegre: Bookman, 2008.

MAGNIER-WATANABE, Remy.; BENTON, Caroline. Management innovation and firm performance: The mediating effects of tacit and explicit knowledge. Knowledge Management Research and Practice, v. 15, n. 3, p. 325-335, 2017. DOI: 10.1057/s41275-017-0058-6

MARAVILHAS, Sérgio.; MARTINS, Joberto. Strategic knowledge management a digital environment: Tacit and explicit knowledge in Fab Labs. Journal of Business Research, v. 94, n. January 2018, p. 353-359, 2019. DOI: 10.1016/j.jbusres.2018.01.061

MENDOZA, Cynthia; BISCHOFF, John; WILLY, Christopher. Measuring the Value of Knowledge Management Practices at Government Research and Development Centers. Knowledge and Process Management, $v 24$, n. 1, p. 14-22, 2017.

PEE, Loo Geoky.; KANKANHALLI, Atreyi. Interactions among factors influencing knowledge management in public-sector organizations: A resource-based view. Government Information Quarterly, v. 33, n. 1, p. 188199, 2016. DOI: 10.1016/j.giq.2015.06.002

SILVA, Ana Paula Nogueira; MIRANDA, Angélica Conceição Dias. Gestão do conhecimento no setor público: um estudo sobre os artigos publicados em periódicos nacionais no período 2005-2015. Encontros Bibli: Revista Eletrônica de Biblioteconomia e Ciência da Informação, v. 23, n. 52, p. 73- 83, maio/ago. 2018. DOI: 10.5007/1518-2924.2018v23n52p73

SHARMA, R. R. K.; DEY, Somen. Managing Tacit and Explicit Knowledge. In:INTERNATIONAL CONFERENCE ON MANAGEMENT AND INFORMATION SYSTEMS (ICMIS), 18., 2018, Bangkok. Proceedings... Bangkok: Chitkara University., 2018. p. 15-20. Disponível em: http://www.icmis.net/icmis18/ICMIS18CD/pdf/S159-final.pdf. Acesso em: 28 ago. 2019.

WILSON, T. D. A problemática da gestão do conhecimento. In:TARAPANOFF, Kira. Inteligência, informação e conhecimento em corporações. Brasília: IBICT; UNESCO, 2006. p. 37-55.

WIIG, Karl. M. Knowledge management in public administration. Journal of knowledge management, v. 6 , n. 3, 224-239, 2002. 